\title{
FREQUÊNCIA DE STAPHYLOCOCCUS AUREUS EM CASOS DE MASTITE BOVINA SUBCLÍNICA, NA REGIÃO SUL DO RIO GRANDE DO SUL
}

\author{
F.S. Bandeira' ${ }^{1}$, T. Picoli ${ }^{1}$, J.L. Zani ${ }^{1}$, W.P. da Silva ${ }^{3}$, G. Fischer ${ }^{2}$ \\ ${ }^{1}$ Universidade Federal de Pelotas, Faculdade de Veterinária, Laboratório de Bacteriologia e Saúde Popula- \\ cional, CP 354, CEP 96010-900, Pelotas, RS, Brasil. E-mail: bandeiravett@gmail.com
}

\section{RESUMO}

A mastite bovina é uma doença importante na exploração leiteira, não apenas pelas perdas econômicas diretas que promove, mas também pelas perdas indiretas e o potencial risco à saúde pública. Dentre as principais causas de infecções intramamárias, destacam-se as bactérias do gênero Staphylococcus spp., sendo que Staphylococcus aureus é o agente etiológico predominante em mastite subclínica. O objetivo desse trabalho foi verificar a frequência de mastite subclínica em oito rebanhos localizados na região Sul do Rio Grande do Sul (Brasil) e a relação da enfermidade com a presença de $S$. aureus. Adicionalmente, pesquisou-se a presença de $S$. intermedius e $S$. hyicus nas amostras de leite obtidas. Para identificação da doença, utilizou-se o California Mastitis Test (CMT). A identificação da espécie de Staphylococcus spp. foi feita em meio de cultura ágar BairdParker, com posterior confirmação das colônias suspeitas em coloração de gram, prova de catalase, pesquisa de coagulase livre e pesquisa de termonuclease. A mastite subclínica foi constatada em $53,6 \%$ dos animais testados. A presença de Staphylococcus coagulase positiva foi identificada em $12,6 \%$ dos animais com mastite subclínica. Nesses mesmos animais, a bactéria identificada como S. aureus foi o agente etiológico presente em $17,6 \%$ dos casos. Adicionalmente, pode-se perceber que, dentre o grupo identificado como coagulase positiva, $85,7 \%$ corresponderam a $S$. aureus, enquanto $8,5 \%$ mostraram características bioquímicas compatíveis com $S$. intermedius e $5,8 \%$ foram consideradas S. hyicus.

PALAVRAS-CHAVE: Coagulase, leite, intermedius, hyicus.

\begin{abstract}
FREQUENCY OF STAPHYLOCOCCUS AUREUS FROM BOVINE SUBCLINICAL MASTITIS CASES, IN SOUTHERN RIO GRANDE DO SUL, BRAZIL. Bovine mastitis is an important disease in dairy farming, not only by promoting direct economic losses, but also for indirect losses and the potential risk to public health. The main causes of intramammary infections include the bacteria of the genus Staphylococcus spp., Staphylococcus aureus being the predominant etiologic agent in subclinical mastitis. The aim of this study was to determine the frequency of subclinical mastitis in eight herds from southern Rio Grande do Sul (Brazil) and the relationship of the disease with the presence of S. aureus. In addition, we checked for the presence of S. intermedius and S. hyicus in the milk samples obtained. For identification of the disease, we used the California Mastitis Test (CMT). Identification of Staphylococcus spp. species was made in BaridParker agar culture medium, with subsequent confirmation of suspected colonies by way of Gram stain and catalase test along with free-coagulase and thermonuclease research. Subclinical mastitis was identified in $53.6 \%$ of animals tested. The presence of coagulase-positive Staphylococcus was identified in $12.6 \%$ of animals with subclinical mastitis. In these same animals, bacteria identified as $S$. aureus were the etiologic agent present in $17.6 \%$ of cases. Additionally, it was revealed that among the group identified as coagulase positive, $85.7 \%$ corresponded to $S$. aureus, while $8.5 \%$ had biochemical characteristics consistent with $S$. intermedius and $5.8 \%$ were considered S. hyicus.
\end{abstract}

KEY WORDS: Coagulase, milk, intermedius, hyicus.

${ }^{2}$ Universidade Federal de Pelotas, Faculdade de Veterinária, Laboratório de Virologia e Imunologia, Pelotas, RS, Brasil. ${ }^{3}$ Universidade Federal de Pelotas, Faculdade de Agronomia "Eliseu Maciel", Laboratório de Microbiologia dos Alimentos, Pelotas, RS, Brasil. 


\section{INTRODUÇÃO}

A mastite bovina é uma enfermidade de significativa importância econômica (PEREIRA et al., 2010), acometendo praticamente todos os rebanhos produtivos mundiais. É uma doença com aspectos multifatoriais (ANAYA-LOPEZ et al., 2006), decorrente da colonização do tecido secretor do úbere por agentes patogênicos (TALbot; LacAsse, 2005). As perdas ocasionadas pela mastite decorrem da menor quantidade de leite produzido (LADEIRA, 2007). Além disso, ocorre diminuição da qualidade do leite dos quartos afetados (OliverRa et al., 2011) com alterações na sua composição (MA et al., 2004), que resultam em interferência na tecnologia industrial para elaboração de derivados (REBHUN, 2000).

A mastite provoca alterações físicas, químicas e microbiológicas no leite produzido (RADOstits et al., 2002), as quais servem de critérios para a classificação da enfermidade e indicativo de diagnóstico inicial da doença, usando-se as alterações visuais diretas no leite ordenhado (formação de grumos e alterações de cor) ou indiretas, percebidas através do teste de CMT (California Mastitis Test) (Costa, 2008).

O gênero Staphylococcus spp. compreende o principal gênero envolvido em casos de mastite subclínica (PYÖRÄLÄ; TAPONEN, 2009). A participação da espécie Staphylococcus aureus, um patógeno que pode ser rotineiramente encontrado no úbere de bovinos, merece destaque como importante espécie causadora de mastite (BADOSH; Melo, 2011). Além das perdas econômicas, essa espécie bacteriana representa potencial risco à saúde pública, uma vez que apresenta a capacidade de produzir enterotoxinas termoestáveis (ViçosA et al., 2010).

O objetivo desse trabalho foi pesquisar a ocorrência da mastite subclínica em rebanhos bovinos da região sul do Rio Grande do Sul e a frequência de $S$. aureus presentes nesses casos.

\section{MATERIAL E MÉTODOS}

As amostras de leite utilizadas nesse estudo foram obtidas em oito propriedades rurais, localizadas na região Sul do Estado do Rio Grande do Sul. Os animais utilizados nesse estudo estavam divididos em seis rebanhos da raça Jersey e dois rebanhos da raça Holandesa, submetidos a duas ordenhas diárias com intervalo de 10 a 12 horas entre cada uma delas. O número total de vacas em diferentes estágios de lactação, nas propriedades amostradas, foi de 423 animais, os quais foram submetidos ao teste de CMT (SCHALM; NoOrLANDER, 1957) para pesquisa de mastite subclínica, durante a rotina de ordenha em cada propriedade. O critério para identificar a mastite subclínica seguiu a interpretação do resultado conforme proposto por BELLOTI (1992).

Uma vez observada a presença de mastite subclínica, os tetos representantes de cada quarto afetado sofreram antissepsia com álcool $70^{\circ} \mathrm{GL}$ e aproximadamente $10 \mathrm{~mL}$ de leite foram coletados em tubos de vidro previamente esterilizados, identificados e mantidos em caixas isotérmicas, sendo encaminhadas ao laboratório para as análises microbiológicas.

As amostras provenientes das propriedades pesquisadas foram inoculadas inicialmente em meio de cultura ágar Baird-Parker, usualmente empregado para pesquisar Staphylococcus spp. em alimentos (Viçosa et al., 2010), utilizando a metodologia descrita por BENNET; LANCETT (1995). Consideraram-se como características presuntivas para Staphylococcus spp. as colônias apresentando forma circular, coloração preta ou cinza escura, diâmetro de aproximadamente $2 \mathrm{~mm}$, apresentando uma massa de células esbranquiçada nas bordas e um halo transparente ou zona opaca ao redor da colônia (SiLva et al., 2007).

As colônias suspeitas obtidas na etapa anterior foram submetidas à coloração de gram e prova da catalase. Adicionalmente, foi realizada a pesquisa de coagulase livre, empregando-se a metodologia descrita por YASDANKHAN; Olsen (1998). De forma complementar, ainda foi efetuada a pesquisa de Nuclease Termoestável (termonuclease ou TNAse), utilizando-se a metodologia descrita por SigueIRA (1995).

As colônias bacterianas identificadas como coagulase positiva e/ ou termonuclease positiva foram submetidas às provas de fermentação aeróbica de manitol emaltose seguindo a metodologia einterpretação descritas por BELLOTI (1992) e para a produção de acetoína utilizou-se a metodologia proposta por PhILLIPS; NASH (1985).

O critério utilizado para identificar a espécie de Staphylococcus spp. encontrada foi adaptado de JAY (2000), JABLONSKI; BOHACH (1997) e BELLOTI (1992).

\section{RESULTADOS E DISCUSSÃO}

O uso do CMT identificou mastite subclínica em 227 vacas em lactação, de um total de 423 animais analisados, representando 53,6\% da ocorrência na população amostrada. A variação de mastite subclínica entre as oito propriedades pesquisadas ficou entre $32,2 \%$ e $69 \%$. Oresultado obtido nesse trabalho demonstra que o índice de mastite subclínica é alto, mesmo com o investimento em educação proporcionado pelo serviço de extensão de empresas laticinistas e de instituições de ensino e pesquisa regionais.

A preocupação com a frequência dessa enfermidade não é recente e há uma variação entre os dados obtidos em vários estudos. Assim, os dados 
encontrados são superiores aos 44,7\% de ocorrência dessa enfermidade, relatados por SiLva (1998) em trabalhos com animais da região geográfica próxima à utilizada nesse experimento. Na mesma região geográfica, Ribeiro et al. (2003) encontraram positividade de $37,6 \%$ na prova de CMT. Índices menores que os encontrados nesse trabalho também foram descritos por COSTA (2008) que relata a ocorrência da doença em 9,85\% dos animais pesquisados na região Sul de Minas Gerais. Ainda, OliveIra et al. (2011) descreveram uma prevalência de mastite subclínica de $15,6 \%$ da enfermidade em vacas mestiças da região de Rondon do Pará e LANGONi et al. (2009), analisando rebanhos leiteiros em produção orgânica, encontraram 44,0\% de mastite subclínica.

Entretanto, Costa et al. (1995) verificaram que $72,5 \%$ das vacas provenientes de rebanhos de São Paulo e Minas Gerais apresentavam mastite subclíni$\mathrm{ca}$, demonstrando valores superiores ao encontrados nessa pesquisa.

A presença de Staphylococcus spp. coagulase positivo foi encontrada em $12,6 \%$ dos animais que demonstraram mastite subclínica frente a prova de CMT, com a metodologia de identificação microbiana utilizada. Esse resultado está abaixo da frequência encontrada por Costa (2008), na região Sul de Minas Gerais, que relatou $34,2 \%$ de ocorrência para esse grupo de micro-organismos.

A bactéria S. aureus esteve presente em $17,6 \%$ dos casos identificados de mastite subclínica. Resultado semelhante foi encontrado por OliveIRA et al. (2011) que, estudando mastite subclínica em vacas provenientes de rebanhos mestiços no Pará, encontraram uma prevalência de $17,7 \%$ de mastite subclínica por S. aureus.

Contudo, os dados obtidos na presente pesquisa estão abaixo dos resultados obtidos por OLIVEIRA et al. (2009) que, trabalhando com rebanhos leiteiros de Sergipe, encontraram S. aureus em $21,9 \%$ dos rebanhos leiteiros estudados com mastite subclínica. Nos estudos de Ribeiro et al. (2009), essa espécie bacteriana esteve presente em $25,7 \%$ dos casos de mastite clínica e subclínica. Ainda, LANGONi et al. (2009) demonstraram dados de que 18,2\% das vacas com mastite, no Município de Botucatu, apresentavam infecção por S. aureus. Em proporções semelhantes, SANTOS et al. (2010) relataram uma frequência de 18,7\% para essa espécie bacteriana em casos de mastite na bacia leiteira de Santa Isabel do Oeste, no Estado do Paraná.

Os dados encontrados nesta pesquisa e na bibliografia confirmam a afirmação de SCHLEgelové et al. (2003), que apontaram S. aureus como sendo uma das espécies mais comumente envolvida em casos de infecções intramamárias em bovinos, além de ser a responsável pelas maiores perdas econômicas das explorações leiteiras em todos os continentes.
A frequência relativamente baixa de mastite subclínica por S. aureus, demonstrada nesse trabalho, pode ser explicada, pelo menos em parte, pelo apoio realizado por órgãos defomentojunto aos produtores rurais. Assim, a assimilação dos conhecimentos e a utilização das informações recebidas colaboram na prevenção de disseminação da enfermidade por essa espécie bacteriana em especial, uma vez que o principal momento de sua transmissão ocorre durante a rotina normal de ordenha dos animais.

Dentre as colônias consideradas coagulase positivas, $85,7 \%$ corresponderam a $S$. aureus, enquanto $8,5 \%$ mostraram características bioquímicas compatíveis com $S$. intermedius e 5,8\% foram consideradas S. hyicus.

Costa (2008) demonstra que, das 360 amostras consideradas como estafilococos coagulase positiva, provenientes de rebanhos identificados com mastite na regiãoSul de Minas Gerais, S. aureus foi identificado em $97,7 \%$ das vezes. A frequência de S. intermedius e S. hyicus, para o mesmo grupo foi, respectivamente, $1,1 \%$ e $0,8 \%$. CAPURRO et al. (1999), em trabalho com rebanhos leiteiros da Suíça, demonstraram que 97\% das infecções intramamárias ocasionadas por estafilococos coagulase positiva eram devidas a S. aureus, enquanto que $S$. intermedius foi isolado em $2 \%$ e $S$. hyicus foi identificado em $1 \%$ para esse parâmetro. Embora existam variações nos percentuais encontrados, à semelhança da presente pesquisa, os demais autores também encontraram a predominância de $S$. aureus, seguido de S. intermedius e S. hiycus em casos de mastite, especificamente analisando-se o grupo de estafilococos coagulase positiva.

A espécie S. aureus também foi a principal, dentre o grupo de estafilococos coagulase positiva identificada por SANTOS et al. (2010), em 81\% dos isolamentos, em vacas leiteiras do Oeste do Paraná. Entretanto, esses autores descrevem que $S$. hiycus foi isolado em 15,2\% desse grupo, sendo a segunda espécie mais encontrada. A espécie menos identificada, $S$. intermedius, apareceu em 3,8\% de seus isolamentos.

Os resultados obtidos nesta pesquisa eamparados pelos demais trabalhos da literatura demonstram ser interessante a realização de provas bioquímicas ou fenotípicas adicionais para identificação da espécie envolvida em infecções intramamárias.

Em $72,5 \%$ das cepas identificadas como $S$. aureus, ocorreu a produção de coagulase e termonuclease. SILVA (1998), trabalhando com rebanhos leiteiros da região Sul do Rio Grande do Sul, encontrou todas as cepas positivas para ambas as provas.

As cepas identificadas como S. hiycus mostraram variação na capacidade de produção de coagulase e termonuclease. Assim, desta espécie, verificouse que $71,4 \%$ expressaram apenas a produção de termonuclease, enquanto $14,3 \%$ produziram apenas coagulase. Ambas as enzimas foram produzidas por 
14,3\% das cepas. Esse resultado pode ser considerado normal, uma vez que a espécie $S$. hyicus éconsiderada como sendo coagulase variável, conforme HASLER et al. (2008).

A produção de termonucleasee coagulase ocorreu em todas as cepas identificadas como $S$. intermedius.

Os dados obtidos com a utilização da pesquisa de termonuclease permitem indicar a sua utilização como uma prova auxiliar na identificação de Staphylococcus spp. Afinal, trata-se de uma prova de fácil execução, pouca subjetividade na leitura e que pode ser facilmente adaptada à rotina laboratorial. Porém, ela não deve servir como substituta a pesquisa de coagulase, mas sempre utilizada no sentido de complementação.

Os resultados obtidos nesse trabalho permitem concluir que a frequência de mastite subclínica nos rebanhos estudados é alta, sendo que em 17,6\% dos casos o agente etiológico isolado foi $S$. aureus. Embora a mastite seja uma doença de difícil erradicação na exploração leiteira, cuidados relacionados ao manejo durante a ordenha devem ser explorados de melhor forma, a fim de evitar a disseminação de agentes infecciosos.

\section{REFERÊNCIAS}

ANAYA-LÓPEZ, J.L.; CONTRERAS-GUZMÁN, O.E.; CÁRABEZ-TREJO, A.; BAIZABAL-AGUIRRE, V.M.; LÓPEZ-MEZA, J.E.; VALDEZALARCÓN, J.J.; OCHOA-ARZOSA, A. Invasive potential of bacterial isolates associated with subclinical bovine mastitis. Research in Veterinary Science, v.81, n.3, p.358-361, 2006. Disponível em: <http://www.sciencedirect.com/science/article/ pii/S0034528806000671>. Acesso em: 31 mar. 2011.

ARAÚJO, W.P. Staphylococcus aureus em leite cru. Caracterização da origem provável, humana ou bovina, das cepas isoladas. Hora Veterinária, v.9, n.49, 1989.

BANDOCH, P.; MELO. Prevalência de mastite bovina por Staphylococcus aureus: uma,revisão bibliográfica. Publicatio UEPG: Ciências Biológicas e da Saúde. Ponta Grossa, v17, n.1, p.47-51, 2011. Disponível em: <http:// www.revistas2.uepg.br/index.php/biologica/article/ view/2592/2455>. Acesso em: 28 jan. 2013.

BELLOTI, V. Mastite subclínica bovina: ocorrência, caracterização bioquímica e perfil plasmidial dos Staphylococcus coagulase negativos. 1992. 95f. Dissertação. (Mestrado em Ciências Farmacêuticas) - Faculdade de Ciências, Farmaceuticas, Universidade de São Paulo, São Paulo, 1992.

BENNETT, R.W.; LANCETTE, G.A. Staphylococcus aureus. In: FDA's Bacteriogical Analytical Manual. 8.ed. Gaithesburg: FDA, 1995. p.12.01-12.05.

CAPURRO, A.; CONHA, C.; NILSON, L.OSTENSSON, $\mathrm{K}$. Identification of coagulase-positive staphylococci isolated from bovine milk. Acta Veterinaria Scandinavica, v.40, n.4, p.315-321, 1999.

COSTA, G.M. Mamite bovina em rebanhos leiteiros da região sul do estado de Minas Gerais. 2008. 123p. Tese (Doutorado em Ciência Animal) - Escola de Veterinária, Universidade Federal de Minas Gerais, Belo Horizonte, 2008.

COSTA, E.O.; MELVILLE, P.A.; RIBEIRO, A.R. Índices de mastite bovina clínica e subclínica nos estados de São Paulo e Minas Gerais. Revista Brasileira de Medicina Veterinária, v.17, n.5, p.215-217, 1995.

DUTTA, G.N.; SAXENA, R.K.; BURAGOHAIN, J. Economic implications of treatment of lactating cows for subclinical mastitis. Indian Veterinary Journal, v.72, p.420-422, 1995.

HARVEY, J.; GILMOUR, A. Applications of current methods for isolation and identification of Staphilococci in raw bovine milk. Journal of Applied Microbiology, v.59, p.207-221, 1985.

HASSLER, C.; NITZSCHE, S.; IVERSEN, C.; ZWEIFEL, C.; STEPHAN, R. Characteristics of Staphylococcus hyicus strains isolated from pig carcasses in two different slaughterhouses. Meat Science, v.80, n.2, p.505-510, 2008. Disponível em: <http:// www.sciencedirect.com/science/ article/pii/S0309174008000326>. Acesso em: 22 ago. 2011.

HILL, B.M. The thermo-stable nuclease test as a method for identifying Staphylococcus aureus. Australian Journal of Dairy Technology, v.38, n.3, p.95-96, 1983.

JABLONSKY, L.M.; BOHACH, G.A. Staphylococcus aureus. In: DOYLE, M.P.; BEUCHAT, L.R.; MONTVILLE, T.J. (Ed). Food microbiology: fundamentals and frontier. Washington: ASM Press, 1997. p.353-376.

JAY, J.M. Staphylococcal Gastroenteritis. In: JAY, J.M.; LOESSNER, M.J.; GOLDEN, D.A. (Ed.). Modern food microbiology. 6.ed. Maryland: Aspen Publishers, 2000. p.441-459.

LADEIRA S.R.L. Mastite bovina. In: RIET-CORREA F; SCHILD A.L.; LEMOS R.A.A.; BORGES J.R.J. (Ed). Doenças de ruminantes e eqüídeos. 3.ed. Santa Maria: Pallotti, 2007. p.359-370.

LANGLOIS, B.E.; PARLINDUNGAN, A.K.; HARMON, R.J.; AKERS, K. Biochemical characteristics of Staphylococcus species of human and bovine origin. Journal of Food Protection, v.53, n.2, p.119-126, 1990.

LANGONI, H.; SAKIYAMA, D.T.P.; GUIMARÃES, F.F.; MENOZZI, B.D.; SILVA, R.C. Aspectos citológicos e microbiológicos do leite em propriedades no sistema orgânico de produção. Pesquisa Veterinária Brasileira, v.29, n.11, p.881-886, 2009.

MA, J; COCCHIARO J.; LEE J. Evaluation of serotypes of Staphylococcus aureus strains used in the production 
of a bovine mastitis bacterin. Journal of Dairy Science, v.87, n.1, p.178-182, 2004. Disponível em: <http:// www.sciencedirect.com/science/article/pii/ S0022030204731562>. Acesso em: 9 abr. 2011.

NADER FILHO, A.; ROSSI JUNIOR, O. D.; SCHOCKENITURRINO, R.P. Mastite subclínica em rebanhos produtores de leite tipo "B". Arquivos Brasileiros de Medicina Veterinária e Zootecnia, v.35, n.5, p.621-629, 1983.

OLIVEIRA, A.A.; MELO, C.B.; AZEVEDO, H.C. Diagnóstico e determinação microbiológica da mastite em rebanhos bovinos leiteiros nos tabuleiros costeiros de Sergipe. Ciência Animal Brasileira, v.10, n.1, p.226-230, 2009. Disponível em: <http://www.revistas.ufg.br/ index.php/vet/article/download/ 1780/4589>. Acesso em: 13 jul. 2011.

OLIVEIRA, C.M.C.; SOUSA, M.G.S.; SILVA, N.S.; MENDONÇA, C.L.; SILVEIRA, J.A.S.; OAIGEN, R.P.; ANDRADE, S.J.T.; BARBOSA, J.D. Prevalência e etiologia da mastite bovina na bacia leiteira de Rondon do Pará, estado do Pará. Pesquisa Veterinária Brasileira, v.31, n.2, p.104-110. 2011. Disponível em: <http://www.scielo. br/pdf/pvb/v31n2/02.pdf>. Acesso em: 15 jul. 2011.

PEREIRA, U.P.; OLIVEIRA D.G.S.; MESQUITA L.R.; COSTA, G.M.; PEREIRA L.J. Efficacy of Staphylococcus aureus vaccines for bovine mastitis: A systematic review. Veterinary Mocrobiology, v.14, n.1/2, p.117-124, 2010. Disponível em: <http:/ / www.sciencedirect.com/science/ article/pii/S0378113510004761>. Acesso em: 31 mar. 2011.

PHILLIPS, E.; NASH, P. Culture media. In: LENETTE, E.H.; BALOWS, A.; HAUSLER, W.J.; SHADOMY, H.J. (Ed.). Manual of clinical microbiology. 4.ed. Washington: American Society for Microbiology, 1985. p.1051-1092.

PYÖRÄLÄ, S.; TAPONENA, S. Coagulase-negative staphylococci-emerging mastitis pathogens. Veterinary Microbiology, v.134, n.1/2, p.3-8, 2009. Disponível em: <http://www.sciencedirect.com/science/article/pii/ S037811350800357X>. Acesso em: 4 abr. 2011.

RADOSTITS, O.M.; MAYHEW, I.G.J.; HOUSTON, D.M. Exame clínico e diagnóstico em veterinária. Rio de Janeiro: Guanabara, 2002. 604p.

REBHUN, W.C. Doenças do gado leiteiro. São Paulo: Roca, 2000.646p.

RIBEIRO, M.E.R.; PETRINI, L.A.; AITA, M.F.; BALBINOTTI, M.; STUMPF JUNIOR, W.; GOMES, J.F.; SCHRAMM, R.C.; MARTINS, P.R.; BARBOSA, R.S. Relação entre a mastite clínica, subclínica infecciosa e não infecciosa em unidades de produção leiteiras na região sul do Rio Grande do Sul. Revista Brasileira de Agrociência, v.9, n.3, p.287-290, 2003.

RIBEIRO, M.G.; GERALDO, J.S.; LANGONI, H.; LARA G.H.B.; SIQUEIRA, A.K.; SALERNO, T.; FERNANDES, M.C. Microrganismos patogênicos, celularidade e resí- duos de antimicrobianos no leite bovino produzido no sistema orgânico. Pesquisa Veterinária Brasileira, v.29, n.1, p.52-58, 2009.

SANTOS, L.L.; PEDROSO, T.F.F.; GUIRRO, E. Perfil etiológico da mastite bovina na bacia de Santa Isabel do Oeste, Paraná. Ciência Animal Brasileira, v.11, n.4, p.860-866, 2010. Disponível em: <http://www.revistas. ufg.br/index.php/vet/article/download/3654/8360>. Acesso em: 3 jun. 2001.

SCHALM, O.W.; NOORLANDER, D.D. Experiments and observation leading to development of California Mastitics Test. Journal of the American Veterinary Medical Association, v.69, p.1708-1720, 1957.

SCHLEGELOVÁ, J.; DENDIS, M.; BENEDÍK, J.; BABÁK, V.; RYSÁNEK, D. Staphylococcus aureus isolates from dairy cows and humans on farms differ in coagulase genotype. Veterinary Microbiology, v.92, p.327-334, 2003. Disponível em: <http:/ / www.sciencedirect.com/science/article/pii/S0378113502004091>. Acesso em: 11 ago. 2011.

SCHOKEN-ITURRINO, R.P.; NADER FILHO, A; FURLANETTO, S.M.P.; ROSSI JÚNIOR, O.D. Pesquisa de $S$. aureus enterotoxigênicos em amostras de leite de vacas mamíticas. Ars Veterinária, v.2, n.1, p.69-74, 1986.

SILVA, W.P. Caracterização fenotípica e genotípica de cepas de Staphylococcus aureus isolados de leite de vacas com mamite subclínica e de outras fontes em propriedades produtoras de leite. 1998. 98p. Tese (Doutorado - Faculdade de Ciências Farmacêuticas) - Universidade de São Paulo, São Paulo, 1998.

SILVA, N.; JUNQUEIRA, V.C.A.; SILVEIRA, N.F.A.; TANIWAKI, M.H.; SANTOS, R.F.S.; GOMES, R.A.R. Staphylococcus aureus. In: (Ed.). Manual de métodos de análise microbiológica de alimentos. São Paulo: Varela, 2007. p.137-148.

SIQUEIRA, R.S. Manual de microbiologia dos alimentos. Brasília: Embrapa, 1995. 159p.

TALBOT B.G.; LACASSE P. Progress in the development of mastitis vaccines. Livestock Production Science, v.98, n.1/2, p.101-113, 2005. Disponível em <http://www. sciencedirect.com/science/article/pii/ S0301622605002897>. Acesso em: 9 abr. 2011.

VARALDO, P.E.; KILPPER-BALZ, R.; BIAVASCO, F.; SATTA, G.; SCHLEIFER, K. H. Staphylococcus delphini sp. nov., a coagulase-positive species isolated from dolphins. International Journal of Systematic Bacteriology, v.18, n.4, p.436-439, 1988.

VIÇOSA, G.M.; MORAES, P.M.; YAMAZI, A.K.; NERO, L.A. Enumeration of coagulase and thermonuclease-positive Staphylococcus spp. in raw milk and fresh soft cheese: an evaluation of Baird-Parker agar, rabbit plasma fibrinogen agar and the Petrifilm ${ }^{\mathrm{TM}}$ Staph Express count system. Food Microbiology, v.27, n.4, p. 447-452, 2010. Disponível 
em: <http:/ / www.sciencedirect.com/science/article/ pii/S0740002009002846>. Acesso em: 14 abr. 2011.

YAZDANKHAN, S.P.; OLSEN, E. Simple and direct detection of Staphylococcus aureus in milk by a tube coagulase test. Letters in Applied Microbiology, v.27. p.111-115, 1998.

Recebido em 29/8/11

Aceito em 30/10/12 